\title{
FEATURES OF THE SEX-ROLE SPHERE OF GIRLS-ADOLESCENTS WITH VIOLATIONS OF THE MENSTRUAL FUNCTION
}

\section{Alla Gryshko ${ }^{1}$}

DOI: https://doi.org/10.30525/978-9934-588-15-0-120

Abstract. The article is devoted to the study of the characteristics of the sex-role sphere of personality of adolescent girls with gynecological pathology using pubertal bleeding and secondary oligomenorrhea as an example. Menstrual dysfunctions occupy a leading role in the structure of adolescent gynecological morbidity, as evidenced by frequent relapses and insufficient treatment effectiveness, which makes studying the formation factors of girls' reproductive potential an urgent research task. The aim of the work is to study the characteristics of the sex-role sphere of adolescent girls suffering from menstrual dysfunction, which can act as possible internal conditions for the development and course of the disease. The main tasks were identified as analysis of the characteristics of the organization and functioning of the sex-role sphere of teenage girls with pubertal bleeding and secondary oligomenorrhea. The theoretical and methodological basis of the study was: the biopsychosocial approach, gender and gender-role approach in psychology, as well as modern scientific studies of medical and psychological factors in the formation of menstrual dysfunction in adolescent girls. The study involved 287 teenage girls: 187 people suffering from menstrual dysfunction and 100 somatically healthy girls as a control group. All adolescents were divided into two age subgroups: 13-14.5 years old and 15-17 years old. Scientific research was carried out on the basis of the Department of Pediatric and Adolescent Gynecology of the Institute for Child and Adolescent Health at the National Academy of Medical Sciences of Ukraine, as well as secondary schools in Kharkov.

The following psychodiagnostic methods were used in the work:

- A.B. Heilbrun sex-role ACL-scale;

- the psychosexual proportion of Dur-Moll L. Szondi;

${ }^{1}$ Candidate of Psychological Sciences, Associate Professor at Department of Psychology, National Aerospace University N.E. Zhukovsky «Kharkiv Aviation Institute», Ukraine 
- the masculinity/femininity scale from PDO-2 A.E. Lichko.

As a result of an empirical study, it was revealed that sex-role deviations have a predisposing role in the formation of menstrual dysfunction. Girls with pubertal bleeding are characterized by a predominance of biogenic masculinity, which limits the assimilation of the feminine patterns of behavior and the feminine component of the self-concept. Girls with secondary oligomenorrhea are characterized by significant severity of biogenic masculinity and the compensatory development of feminine patterns of behavior and attitudes in the self-concept. The organization of the symptom-complex of masculinity/femininity in research groups is characterized by discordance at different levels. In case of puberty bleeding, discordance of the biogenic and behavioral levels with respect to the gender role-concept is observed, and with secondary oligomenorrhea, discordance of the biogenic level with respect to the level of self-concept and behavior is observed. An analysis was made of the determination of models of the structural organization of the symptom-complex of masculinity/femininity, which established the presence of a continuum-adjunctive sex-role model normative for younger adolescents and its preservation as immature in older adolescence in girls with puberty bleeding, as well as the phenomenon of the acceleration of the development of a mature androgynous model of girls with secondary oligomenorrhea. Based on the results of the study, recommendations are given regarding the organization of psycho-correctional work with adolescent girls suffering from menstrual dysfunction.

\section{Introduction}

In recent years, the state of reproductive health of adolescent girls is characterized by a constant deterioration. According to I.E. Aslanyan, M.Yu. Borisenko, E.V. Uvarova, S. Akgül, N. Kanbur [1, p. 34; 2, p. 16; 3, p. 8] prevalence among girls of gynecological pathology is increasing. Its main forms are disorders of menstrual function, which in Ukraine in the structure of gynecological morbidity in adolescents account for $61-63 \%$ [4, p. 36].

Menstrual dysfunction negatively affects the overall development of the personality, transforms all spheres of life of teenage girls, complicates the process of becoming a woman, the formation of inter-partner communication, often accompanied by feelings of shame, anxiety, inferiority, pronounced emotional lability, etc. [5, p. 179]. 
A number of researchers note that during puberty, the selective sensitivity of the reproductive system to psychological factors increases. $[1$, p. 33 ; 5 , p. $180 ; 6$, p. 39]. Among the leaders note: the nature of family relationships and the conditions of upbringing, difficulties in communicating with peers, stress during educational overloads [4, p. 48], personality characteristics of adolescents, namely certain types accentuation of character [7, p. 203], stress and the consequences of psychological trauma, difficulties in undergoing critical phases of psychosexual development and socialization [2, p. 18]. So, the analysis of the formation of menstrual dysfunction should be carried out taking into account psychological factors. However, studies in this direction are few, sometimes contradictory. The psychosexual aspect of the gynecological pathology of adolescents, the influence of sex-role factors (which are one of the vectors of psychosexual development) generally remain poorly understood. Meanwhile, sex-role structures are basic personality characteristics that play a decisive role in the processes of adaptation, supporting the psychological and psychosomatic health of a person $[8, \mathrm{p} .86]$.

There are some data $[2$, p. 21] on the role of gender-role identity disorders in the formation of pubertal bleeding, secondary oligomenorrhea and other menstrual dysfunctions, namely, prevalence in girls of male aspects of gender identity. They are associated with such features as perfectionism, stenicism, leadership qualities, the prevalence of the desire to be distinguished from many. In addition, the presence of severe narcissistic and castration anxieties is indicated. The research results also demonstrate the girls' desire for an ideal athletic body with significant muscle mass (in patients with pubertal bleeding), for strength, sportiness, and possession of willpower (in patients with pubertal bleeding, secondary oligomenorrhea and secondary amenorrhea), which are reflected in their behavior. A.S. Kocharyan revealed the presence of sex-role transformation in adolescent girls suffering from pubertal bleeding. At the same time, the author claims that: "Sex-role formations are core in the personality structure, and constitute the entire personality system, being one of the definitions of psychological and psychosomatic health" [8, p. 132]. Certainly, the data indicate that deviations in the structure of the sex-role sphere become a factor predisposing to the development of gynecological pathology.

With this in mind, it becomes necessary to study menstrual irregularities in a gender-role context, which will improve the provision of medical and 
psychological assistance to teenage girls, determine ways and methods of psycho-correctional work in order to mitigate the course and consequences of the disease.

Thus, the goal of our study is to study the characteristics of the sex-role sphere of teenage girls suffering from menstrual dysfunction, which can act as possible internal conditions for the development and course of the disease.

As the main tasks, one can single out an analysis of the characteristics of the organization and functioning of the sex-role sphere of teenage girls with pubertal bleeding and secondary oligomenorrhea.

The sex-role sphere of the personality is represented by the symptomcomplex of masculinity/femininity (hereinafter $\mathrm{M} / \mathrm{F}$ ) and, as a result, violations of this sphere can relate to its following aspects:

1) structural characteristics of $\mathrm{M} / \mathrm{F}$;

2) level characteristics $M / F$;

3) features of inter-level connections of $\mathrm{M} / \mathrm{F}$ formations.

Today, it is possible to distinguish three structural models that describe the sex-role sphere of personality: continuum-alternative, continuum-adjunctive and androgynous. The first two models reflect the immature structure of the $\mathrm{M} / \mathrm{F}$ symptom-complex of the early puberty. Beginning with the period of sexual segregation, preparation for the splitting of $\mathrm{M} / \mathrm{F}$ formations occurs a continually alternative sex-role model in boys and a continuum-adjunctive model in girls are replaced by an androgynous (orthogonal) model by the age of 15-16 [9, p. 31]. Psychological M/F formations become independent. The mature androgynous structure is simultaneously integrated and differentiated, which allows it to be considered as complex. In this case, the ideal formation of $\mathrm{M}$ and $\mathrm{F}$. performs the function of integrating a mature sex-role symptom-complex.

It is also known that the study of $\mathrm{M}$ and $\mathrm{F}$ can be carried out at three levels: sociogenic (or the level of self-concept), biogenic and behavioral $[9$, p. 83].

Thus, when describing the sex-role sphere of girls with menstrual dysfunction, it is advisable to rely on the level distribution of $\mathrm{M} / \mathrm{F}$ formations, the study of the concordance/discordance of the $\mathrm{M} / \mathrm{F}$ symptomcomplex at different levels of its functioning, and on the identification of the sex-role model of personality. 
As methods for studying the features of the structure and function of the $\mathrm{M} / \mathrm{F}$ symptom-complex, a number of sex-role scales were used - the ACLscale of sex-role behavior A.B. Heilbrun, Dur-Moll scale in the L. Szondi method, m/f PDQ scale (Psycho-diagnostic questionnaire) - 2 A.E. Lichko. When processing the data, the Fisher angular transformation criterion and the Tay Kendall correlation method were used.

The study was conducted on the basis of the Department of Pediatric and Adolescent Gynecology of the Institute for Child and Adolescent Health of the National Academy of Medical Sciences of Ukraine, as well as secondary schools in Kharkov. The study involved 187 girls suffering from pubertal bleeding (MKX10: N92.2) and secondary oligomenorrhea (MKX10: N 91.4), as well as 100 somatically healthy girls - the control group. All adolescents were divided into two age subgroups: 13-14.5 years old and 15-17 years old. The total number of teenage girls was 287 .

\section{The level organization of the symptom-complex $\mathrm{M} / \mathrm{F}$ of sick girls}

In order to identify the features of the level distribution of $\mathrm{M} / \mathrm{F}$ formations, the concordance/discordance of the $\mathrm{M} / \mathrm{F}$ symptom-complex at different levels of its functioning (sociogenic, behavioral and biogenic) of adolescent girls with menstrual dysfunction, the psycho-diagnostic map A.S. Kocharyan [8, p. 142]. The sociogenic level of the symptom-complex $\mathrm{M} / \mathrm{F}$ was diagnosed using the control adjective scale ACL - A.B. Heilbrun. The $\mathrm{m} / \mathrm{f}$ PDO scale, which is based on the socio-normative concept of $\mathrm{M} / \mathrm{F}$, has the following content: activity-passivity, sociality-egocentrism. The biogenic level of the $\mathrm{M} / \mathrm{F}$ symptom-complex was diagnosed with the Dur-Moll scale of the L. Szondi technique.

At the first stage, in each of the studied groups, the percentage ratio of the types of sex role identity for each level of $\mathrm{M} / \mathrm{F}$ symptom-complex was established (tables 1,2).

From table 1 it can be seen that girls of the first age group suffering from pubertal bleeding at the sociogenic level more often identify themselves as feminine $(45,1 \%)$, as well as androgynous $(39,2 \%)$. These indicators do not distinguish them from the control group. However, in girls with pubertal bleeding, there is a lack of the masculine type of sex-role identity, which indicates the negation of masculine characteristics at the level of selfconcept. Moreover, masculinity indicators are significantly expressed at the 
behavioral and biogenic levels in pubertal bleeding sufferers $(73,6 \%$ and $78,4 \%$ respectively), while females at the behavioral level are dominated by femininity, and feminine characteristics are significantly represented at the biogenic level more often. This suggests that girls with pubertal bleedings have an inter-level sex-role inconsistency (discordance): behavioral masculinity is based on biogenic (deep) masculinity, but it is not accepted at the level of the self-concept, and girls evaluate themselves as feminine. At the same time, in the control group of younger adolescents, inter-level coordination is noted: "androgynous" (48\%) and "feminine" (34\%) girls at the behavioral level have significantly high indicators of femininity. And girls with high biogenic masculinity (64\%) have the opportunity to compensate for it. A.S. Kocharyan in his works noted the existence of inter-level compensation [9, p. 67]. This means that people with pronounced masculine (or feminine) characteristics at the biogenic level can detect feminine (or masculine) traits at the behavioral level and at the level of gender role identity (sociogenic).

Girls of the first age group suffering from secondary oligomenorrhea are significantly more likely, in comparison with control group, to assess themselves as feminine (55\%) and $45 \%$ - as androgynous. At the same time, as with girls with pubertal bleeding, they have a denial of their own masculinity at the level of self-concept $(0 \%)$. In addition, unlike the other groups studied, girls with secondary oligomenorrhea are characterized by a clear gender role identity - the group does not present an undifferentiated type. The trend towards feminization is also observed at the behavioral level. Girls select feminine behavior in $89 \%$ of cases, which significantly distinguishes them from control group. The biogenic level in patients with secondary oligomenorrhea is represented by dominant masculinity, with $25 \%$ of girls having pronounced masculinity $(\mathrm{M}=100 \%$ according to the Dur-Moll L. Szondi scale). Moreover, among 42,5\% of girls with biogenic femininity, there is not a single representative with this emphasized characteristic (when F $=100 \%$ on the Dur-Moll L. Szondi scale). This fact distinguishes girls with secondary oligomenorrhea from a healthy group and suffering from pubertal bleeding. Based on the analysis of the level distribution of $\mathrm{M} / \mathrm{F}$ formations, we can talk about the suppression, tabooing by girls of the secondary oligomenorrhea group of masculine characteristics at the level of self-concept and hyperfeminine orientation at the behavioral level, as excessive compensation for biogenic, deep masculinity. 
Level distribution of $\mathrm{M} / \mathrm{F}$ formations of sick girls of the first age group in comparison with control group

\begin{tabular}{|c|c|c|c|c|c|c|c|}
\hline \multirow{2}{*}{\multicolumn{2}{|c|}{$\begin{array}{c}\text { Symptom } \\
\text { complex } \\
\text { M/F levels }\end{array}$}} & \multicolumn{2}{|c|}{ Frequency \% } & \multirow{3}{*}{$\frac{c}{2,48^{* *}}$} & \multicolumn{2}{|c|}{ Frequency \% } & \multirow{3}{*}{ 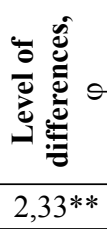 } \\
\hline & & \multirow{2}{*}{$\begin{array}{c}\text { PB } n=49 \\
0\end{array}$} & \multirow{2}{*}{$\begin{array}{c}\mathbf{C G} \mathbf{n}=\mathbf{5 0} \\
6\end{array}$} & & \multirow{2}{*}{$\begin{array}{c}\text { SOM } \\
\mathbf{n}=\mathbf{4 0}\end{array}$} & \multirow{2}{*}{$\begin{array}{c}\mathbf{C G} \mathbf{n}=\mathbf{5 0} \\
6\end{array}$} & \\
\hline \multirow{4}{*}{ 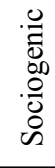 } & $\mathrm{M}$ & & & & & & \\
\hline & $\mathrm{F}$ & 45,1 & 34 & 1,14 & 55 & 34 & $2,00 *$ \\
\hline & $\mathrm{A}$ & 39,2 & 48 & 0,89 & 45 & 48 & 0,28 \\
\hline & $\mathrm{U}$ & 15,7 & 12 & 0,54 & 0 & 12 & $3,32 * *$ \\
\hline \multirow{2}{*}{ 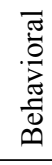 } & M & 73,6 & 38 & $3,8^{* *}$ & 11 & 38 & $3,06^{* *}$ \\
\hline & $\mathrm{F}$ & 26,4 & 62 & $3,8^{* *}$ & 89 & 62 & $3,06 * *$ \\
\hline \multirow{4}{*}{$\begin{array}{l}.0 \\
\overline{8} \\
.00 \\
.00 \\
0\end{array}$} & $\mathrm{M}$ & 78,4 & 64 & $1,6^{*}$ & 57,5 & 64 & 0,63 \\
\hline & $\mathrm{M} !$ & 0 & 12 & $3,22 * *$ & 25 & 12 & $1,6^{*}$ \\
\hline & $\mathrm{F}$ & 21,6 & 36 & $1,6^{*}$ & 42,5 & 36 & 0,63 \\
\hline & $\mathrm{F} !$ & 3,9 & 12 & 1,55 & 0 & 12 & $3,03 * *$ \\
\hline
\end{tabular}

Note: ${ }^{*}-\mathrm{p} \leq 0,05,{ }^{*} *_{-} \mathrm{p} \leq 0,01$;

$\varphi$ - Fisher angular transformation criterion;

A - androgynous type; $\mathrm{M}$ - masculine type;

$\mathrm{F}$ - feminine type;

$\mathrm{U}$ - undifferentiated in a sex-role relation;

$\mathrm{M} !-$ coefficient $\mathrm{M}=100 \%$;

$\mathrm{F} !-$ coefficient $\mathrm{F}=100 \%$;

$\mathrm{PB}$ - pubertal bleeding;

SOM - secondary oligomenorrhea;

$\mathrm{CG}$ - the control group.

Table 2 shows that although in the second age group of sick girls, the features of the inter-level distribution of $\mathrm{M} / \mathrm{F}$ formations are similar to the first age group, a number of distinctive points should be noted. So for the group with pubertal bleeding at the sociogenic level, an increase in the number of girls who rate themselves as androgynous is $(76,5 \%)$. At the same time, there is a negation of masculine characteristics at the level of self-concept. The same indicators are noted in the control group. 
Level distribution of $\mathrm{M} / \mathrm{F}$ formations of sick girls of the second age group in comparison with control group

\begin{tabular}{|c|c|c|c|c|c|c|c|}
\hline \multirow{2}{*}{\multicolumn{2}{|c|}{$\begin{array}{l}\text { Symptom } \\
\text { complex } \\
\text { M/F levels }\end{array}$}} & \multicolumn{2}{|c|}{ Frequency \% } & \multirow{3}{*}{ 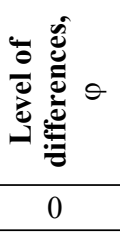 } & \multicolumn{2}{|c|}{ Frequency \% } & \multirow{3}{*}{ 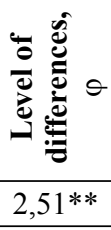 } \\
\hline & & \multirow{2}{*}{$\begin{array}{c}\mathbf{P B} \mathbf{n}=\mathbf{5 0} \\
0\end{array}$} & \multirow{2}{*}{$\begin{array}{c}\mathbf{C G} \mathbf{n}=\mathbf{5 0} \\
0\end{array}$} & & \multirow{2}{*}{$\begin{array}{r}\mathbf{S O M} \\
\mathbf{n}=\mathbf{4 8}\end{array}$} & \multirow{2}{*}{$\begin{array}{c}\mathbf{C G} \mathbf{n}=\mathbf{5 0} \\
0\end{array}$} & \\
\hline \multirow{4}{*}{ 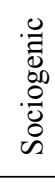 } & $\mathrm{M}$ & & & & & & \\
\hline & $\mathrm{F}$ & 23,5 & 26 & 0,29 & 41,6 & 26 & $1,64 *$ \\
\hline & A & 76,5 & 70 & 0,73 & 45,8 & 70 & $2,45 * *$ \\
\hline & $\mathrm{U}$ & 0 & 4 & $2,02 *$ & 6,3 & 4 & 0,51 \\
\hline \multirow{2}{*}{$\begin{array}{l}\bar{\pi} \\
\frac{0}{0} \\
\frac{\pi}{0} \\
0 \\
0\end{array}$} & M & 62 & 20 & $4,43 * *$ & 19,8 & 20 & 0,03 \\
\hline & $\mathrm{F}$ & 38 & 80 & $4,43 * *$ & 80,2 & 80 & 0,03 \\
\hline \multirow{4}{*}{$\begin{array}{l}.00 \\
\bar{\Xi} \\
.0 \\
.00\end{array}$} & $\mathrm{M}$ & 82,4 & 42 & $4,33 * *$ & 54,2 & 42 & 1,23 \\
\hline & $\mathrm{M} !$ & 5,9 & 12 & 1,08 & 16,7 & 12 & 0,66 \\
\hline & $\mathrm{F}$ & 17,6 & 58 & $4,33 * *$ & 45,8 & 58 & 1,23 \\
\hline & $\mathrm{F} !$ & 0 & 8 & $2,56 * *$ & 0 & 8 & $2,50 * *$ \\
\hline
\end{tabular}

Note: ${ }^{*}-\mathrm{p} \leq 0,05,{ }^{* *}-\mathrm{p} \leq 0,01$;

$\varphi-$ Fisher angular transformation criterion;

A - androgynous type;

$\mathrm{M}$ - masculine type;

$\mathrm{F}$ - feminine type;

$\mathrm{U}$ - undifferentiated in a sex-role relation;

$\mathrm{M} !$ - coefficient $\mathrm{M}=100 \%$;

$\mathrm{F} !$ - coefficient $\mathrm{F}=100 \%$;

PB - pubertal bleeding;

SOM - secondary oligomenorrhea;

$\mathrm{CG}-$ the control group.

Ahigh percentage of "androgynous" teenage girls can be explained, firstly, by age-related changes, the completion of the splitting of $\mathrm{M} / \mathrm{F}$ formations by the age of 15-16 - against the background of the intensive functioning of the endocrine system, an increase in the desire for girls to please boys is observed, normally showing female forms of behavior and suppressing male; the formation of erotic and sexual libido ( 1 phase), the choice of the 
object of attraction. Secondly, this may be a consequence of the introjection of masculine values accepted in European culture. A.S. Kocharyan argued that the cultural norms of female behavior are "artificial," and noted the existence of a gap between deep, biogenic femininity and its presentation at the level of self-concept [8, p. 130]. However, while in the control group the androgynous type is consistent with the prevailing behavioral and biogenic femininity, in the group with pubertal bleeding, masculinity remains dominant at the behavioral level (62\%), and at the biogenic level there is a significant increase in the percentage of girls with masculine characteristics $(82,4 \%)$. Moreover, among $17,6 \%$ of girls with biogenic femininity there is not one with $\mathrm{F}=100 \%$ on the Dur-Moll L. Szondi scale.

The androgynous type also dominates in secondary oligomenorrhea girls $(45,8 \%)$, however, its frequency of occurrence is significantly lower than in the control group (70\%). At the same time, femininity indicators are significantly more often represented $(41,6 \%)$ compared with healthy adolescents $(26 \%)$. Given the high behavioral femininity, it can be argued that the hard line of "feminization", noted in the first age group, is presented in the second. The androgynous orientation of girls with secondary oligomenorrhea seems to be based on biogenic masculinity $(54,2 \%$ of girls, of which $16,7 \%$ have $\mathrm{M}=100 \%$ on the Dur-Moll L. Szondi scale, and pronounced femininity is $0 \%$ ) and, as compensation, hyperfeminin behavioral reactions are observed.

At the second stage, the inter-level connection of the $\mathrm{M} / \mathrm{F}$ formations (in other words, the sociogenic, behavioral and biogenic levels of $\mathrm{M} / \mathrm{F}$ ) was analyzed. Figures 1, 2, and 3 show the corresponding correlation pleiades for each of the studied groups of adolescents.

From Figure 1, it can be seen that in the group of younger adolescents with pubertal bleeding, the relationship of $\mathrm{M}$ and $\mathrm{F}$ formations at the sociogenic level is significantly positive and relies on behavioral and biogenic masculinity. Thus, girls become "hostages" of biogenic masculinity, the scope of which limits both the feminine and masculine self-concept and sexrole behavior. This sex-role structure can be described as undifferentiated when the relations between the individual levels of the $\mathrm{M} / \mathrm{F}$ symptomcomplex are rigidly determined. The second age group does not have significant differences in the structure of inter-level connections within the symptom-complex M/F. Girls of this group, only add a significantly positive correlation of feminine characteristics of behavioral and sociogenic levels. 


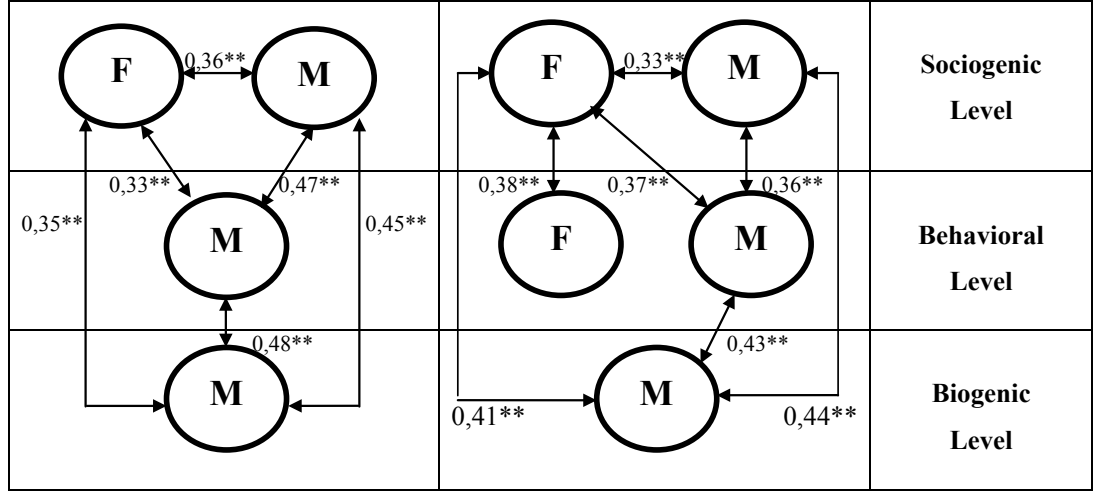

1 age group

2 age group

Figure 1. Correlation pleiades of the relationship of different levels of the symptom-complex $\mathrm{M} / \mathrm{F}$ in the 1st and 2nd age groups of girls with pubertal bleeding

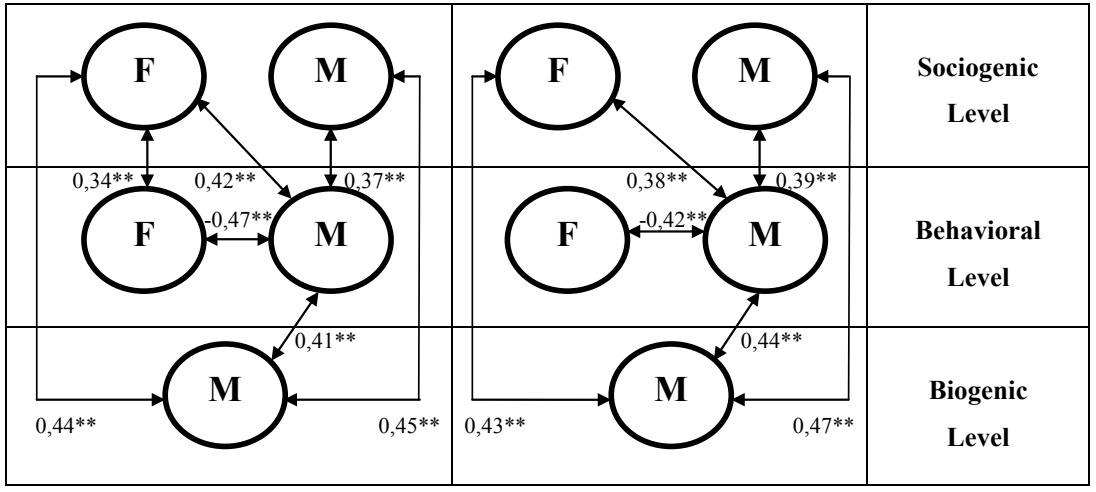

1 age group

2 age group

Figure 2. Correlation pleiades of the relationship of different levels of the symptom-complex $\mathrm{M} / \mathrm{F}$ in the 1 st and $2 \mathrm{nd}$ age groups of girls with secondary oligomenorrhea

This confirms the above assumption that being "deeply" masculine, girls deny the presence of masculine characteristics at the level of the I-image and their behavior. And this, in turn, is evidence of inter-level discordance. 
According to Figure 2 in both age groups of F- and M- formations of the level of self-concept are independent of each other, and at the behavioral level they are generally mutually exclusive (where feminine characteristics significantly dominate, see tables 1,2 ). At the same time, as in the case of girls suffering from pubertal bleeding, there is a rather rigid sex-role structure determined by biogenic masculinity. The peculiarity of girls with secondary oligomenorrhea is hyperfeminin behavior with the suppression of $\mathrm{M}$-formations and the negation of the masculine properties of the personality in the I-image, in order to compensate for the primary, biogenic masculinity. So, girls of this group adhere to behavioral patterns that correspond to the pseudo-normative model of gender-role behavior of women: emphasized passivity, submission, dedication, masochistic inclinations, suffering, passivity, etc. Such behavior can be caused not by desire, but by necessity, by the obligation to adopt a female sexual role.

Thus, the presented structure of inter-level connections within the $\mathrm{M} / \mathrm{F}$ symptom-complex in girls suffering from pubertal bleeding and secondary oligomenorrhea can be described as non-articulated, rigid, not allowing individual levels of the symptom-complex to show relative freedom. This fact greatly complicates the development of adaptive gender roles by a person.

In literature there are indications that a person, in fact, is free in his behavior from "...constant personality structures" [8, pp. 144-145], that his behavior may correspond to the situation, even if it contradicts his personal characteristics ("The phenomenon of the situation and situational conditioning of people's behavior"). In this case, it becomes possible to compensate one level for another, avoiding rigid determination between individual levels of the $\mathrm{M} / \mathrm{F}$ symptom-complex. This option can be observed in the analysis of the inter-level connection of masculinity and femininity formations in adolescent control group.

As can be seen from pic. 3 in the first age group, the relationship of the $\mathrm{M} / \mathrm{F}$ formations of the sociogenic level in healthy girls is significantly positive, which is characteristic of the period of early puberty. A positive correlation is also observed between the F-formations of the behavioral and biogenic levels and $\mathrm{M}$-formations of the same levels. This indicates the consistency of the behavioral and biogenic levels of the $\mathrm{M} / \mathrm{F}$ symptomcomplex in the control group - the behavioral realization of female and male roles is based on the genetic, hormonal aspects of femininity and 


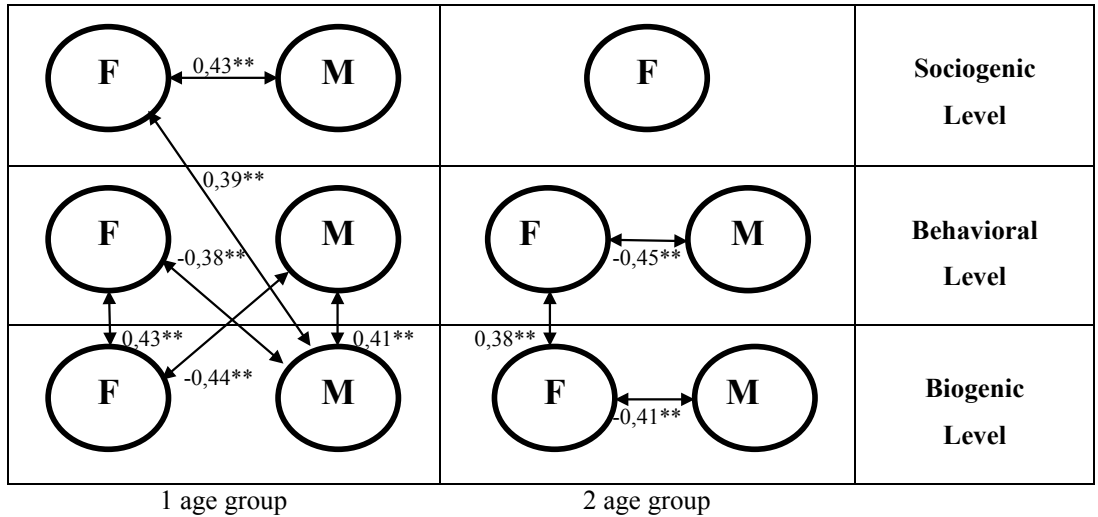

Figure 3. Correlation pleiades of the relationship of different levels of the symptom-complex $\mathrm{M} / \mathrm{F}$ in the 1st and 2nd age groups of girls of the control group

masculinity. At the same time, it can be seen that biogenic masculinity is inversely negatively related to behavioral femininity, as is biogenic femininity with behavioral masculinity. Of interest in the control group is a positive correlation of the femininity of the sociogenic level and biogenic masculinity. Obviously, the adoption of female characteristics as qualities in healthy girls occurs through personal compensator in primary masculinity. In general, inter-level connections within the $\mathrm{M} / \mathrm{F}$ symptom-complex in the first age-related control group differ (in comparison with groups of sick girls) in greater differentiation and articulation.

In the second age group, one observes:

- the lack of communication between $\mathrm{M} / \mathrm{F}$ formations of a sociogenic level, which corresponds to their age category;

- lack of links between biogenic, behavioral and sociogenic masculinity; c) the lack of connections between biogenic masculinity and femininity of behavioral and sociogenic levels;

- the dominant behavioral femininity is based on biogenic, which ensures the consistency of these levels of the symptom complex;

$-\mathrm{M} / \mathrm{F}$ education within the framework of the behavioral level, as well as biogenic mutually exclusive. 
The absence of linear relationships between the level formations of the $\mathrm{M} / \mathrm{F}$ symptom-complex indicates that there may be multivalued relationships between them. And this, in turn, provides an opportunity for inter-level compensation. This state of affairs allows girls to more flexibly adapt to different gender roles, appropriate to a particular situation. As a result, role-playing flexibility and a wide range of gender-specific behavior are observed in control group girls.

\section{Characterization of infrastructural relationships of $\mathrm{M} / \mathrm{F}$ formations of sick girls}

The nature of the infrastructural connections of $\mathrm{M} / \mathrm{F}$ formations is determined by the organization model of the symptom-complex $\mathrm{M} / \mathrm{F}$ : continually alternative, androgynous and continuum-adjuctive [9, p. 30]. The presence of a particular model of the sex-role sphere of an individual determines the level of its maturity, a normative or deviant path of development, and features of the personality's functioning in different areas. At the same time, relying on the remark of A.S. Kocharyan [9, p. 31] that the androgynous and continuum-adjunctive models function only at the sociogenic level of the symptom-complex, the relationships of $\mathrm{M}$ and $\mathrm{F}$ indicators of the A.B. Heilbrun sex-role scale were studied (diagnosing the sex role "I am the concept" of personality).

Table 3 presents the correlation coefficients of $\mathrm{M}$ and $\mathrm{F}$ parameters in groups of sick girls of different ages.

Table 3

\section{The relationship of $\mathrm{M} / \mathrm{F}$ formations in different age groups of adolescent girls suffering from pubertal bleeding and secondary oligomenorrhea}

\begin{tabular}{|l|c|c|c|c|}
\hline \multirow{2}{*}{$\begin{array}{c}\text { Sample } \\
\text { description }\end{array}$} & \multicolumn{2}{|c|}{ PB } & \multicolumn{2}{c|}{ SOM } \\
\cline { 2 - 5 } & $\begin{array}{c}\text { Girls 13-14,5 } \\
\text { y.o. } \mathbf{n = 4 9}\end{array}$ & $\begin{array}{c}\text { Girls15-17 y.o. } \\
\mathbf{n = 5 0}\end{array}$ & $\begin{array}{c}\text { Girls 13-14,5 } \\
\text { y.o. } \mathbf{n}=\mathbf{4 0}\end{array}$ & $\begin{array}{c}\text { Girls15-17 y.o } \\
\mathbf{n}=\mathbf{4 8}\end{array}$ \\
\hline $\begin{array}{l}\text { Connection } \\
\text { level, } \tau\end{array}$ & $0,36^{* *}$ & $0,33^{* *}$ & 0,19 & 0,16 \\
\hline
\end{tabular}

Note: ${ }^{*}-p \leq 0,05, * *-p \leq 0,01$;

$\tau$ - Kendell correlation coefficient;

PB - pubertal bleeding;

SOM - secondary oligomenorrhea. 
As can be seen from table 3 in the first age group of adolescent girls suffering from pubertal bleeding, the relationship of $\mathrm{M} / \mathrm{F}$ formations is significantly positive, which is typical for the continuum-adjunct sex-role model. Thus there is an unsplit internal unity of masculinity and femininity in the personality structure of girls of this group. This model is normative for girls up to 15-16 years of age and represents the immature structure of the symptom complex of early puberty. A.S. Kocharian notes that the unity of M and $\mathrm{F}$ formations within the framework of this model is contradictory: on the one hand, girls negatively evaluate, criticize representatives of their gender, overestimating the male; on the other hand, girls accept stereotypes, patterns of behavior characteristic of the female space [9, p. 31]. As indicated above, starting from the period of sexual segregation, the beginning of preparation for the splitting of $\mathrm{M} / \mathrm{F}$ formations should be observed. At this time, girls want to like the opposite sex, show female forms of behavior and suppress male ones. And by the age of 15-16, the splitting of $\mathrm{M}$ and $\mathrm{F}$ structures is completed - there is a transition to a mature androgynous sex-role model, when independence relations arise between $\mathrm{M} / \mathrm{F}$ indicators. However, in the second age group of girls suffering from pubertal bleeding, we observe the same sex-role model as in the first age group - the continuum-adjuctive one. This fact indicates that the development of the sex-role sphere of girls with pubertal bleeding does not meet age standards, indicates the immaturity of the structure of the $\mathrm{M} / \mathrm{F}$ symptom-complex. Moreover, the data on the control group (1st age group $-0,42 * * ; 2$ nd age group $-0,19$ ) correspond to the correct formation of the organization models of the symptom-complex M/F.

As for the first and second age groups suffering from secondary oligomenorrhea, here you can see the lack of connection between the $\mathrm{M}$ and $\mathrm{F}$ formations - the relationship of $\mathrm{M}$ and $\mathrm{F}$ is represented by the androgynous sex-role model. According to A.S. Kocharyan, despite the fact that the androgynous sex-role model is formed normally by the age of 15-16, it is possible to observe inadequate, invert sex-role models in the early puberty [9, p. 67]. So, A.S. Kocharyan and N.I. Trikosa faced a similar case - in adolescent boys with impaired lipid metabolism, an androgynous sex-role model was identified. They identified this phenomenon as "accelerating the formation of mature relationships within the framework of the M/F symptom complex" and was associated with a number of features of the individual development of adolescents 
[9, p. 68]. Finding the answer to why girls suffering from secondary oligomenorrhea, during the period of early puberty $\mathrm{M}$ and $\mathrm{F}$ education go through the stage of formation in the "torn mode", most likely, should be carried out in the plane of parental relationships and their negative impact on the sex-role sphere of the child - problem identification with the mother; emotionally closed relationships with the father (or their absence); distant, "cold" relationships between parents when there are no opportunities for the formation of an adequate sex-role behavior. This state of affairs leads to insufficient differentiation, the study and consolidation of female gender-role attitudes in the realization of models of masculinity and femininity. This is confirmed by the results of our other study, regarding the peculiarities of girls with menstrual dysfunction of the stages of psychosexual development [10, pp. 106-108]: at the first stage of psychosexual development, it was noted that with proper sexual identity in girls with secondary oligomenorrhea there is insufficient differentiation in settings related to gender, the emphasis on girls was on gender differences in behavior; at stage II, there were difficulties in the development, study and consolidation of their female gender role attitudes, with the awareness of models of masculinity and femininity.

Table 4 presents the types of sex-role models of girls of different groups, and their adequacy to the age period is noted.

Table 4

Variants of sex-role models in different groups of teenage girls

\begin{tabular}{|c|c|c|}
\hline Group & Sex role model & Characteristic \\
\hline PB1 & continuum-adjuctive & adequate model \\
\hline PB2 & continuum-adjuctive & inadequate model \\
\hline SOM1 & androgynous & inadequate model \\
\hline SOM2 & androgynous & adequate model \\
\hline CG1 & continuum-adjuctive & adequate model \\
\hline CG2 & androgynous & adequate model \\
\hline
\end{tabular}

Note: PB - pubertal bleeding;

SOM - secondary oligomenorrhea;

$\mathrm{CG}-$ the control group. 


\section{Conclusions}

The analysis of the characteristics of the sex-role sphere of adolescent girls suffering from menstrual dysfunction in comparison with control group allows us to state the following:

1.In the $\mathrm{M} / \mathrm{F}$ symptom-complex, discordant (inconsistent) $\mathrm{M}$ and $\mathrm{F}$ traits coexist, as a result of which, the sex-role structure of the personality of patients can be described as internally contradictory. So, sufferers of pubertal bleedings emphasize their feminine essence at the sociogenic level, with primary masculinity (biogenic level) and high masculinity at the behavioral level. Girls suffering from secondary oligomenorrhea, with the same primary masculinity, note a hyperfeminin orientation both at the behavioral and at the level of self-concept, and the girls completely deny the possibility of masculine traits at these levels. All this indicates the interlevel inconsistency of $\mathrm{M} / \mathrm{F}$ entities and the presence of gender-role conflict within the individual.

2.The non-differentiation, insufficient articulation of inter-level connections of $\mathrm{M} / \mathrm{F}$ formations, which become the cause of gender-role imbalance within the person, leads to rigidity of gender-role behavior, difficulties in mastering a wide gender repertoire of roles, inadequate self-image.

3.For the 2nd age group, suffering from pubertal bleeding, and the 1st age group with secondary oligomenorrhea, the presence of inadequate gender-role models that do not meet age norms is true. Girls with pubertal bleeding retain the infantile structure of the sociogenic level of the $\mathrm{M} / \mathrm{F}$ symptom-complex, organized by the continuumadjuctive model, and the androgynous sex-role model remains unformed. In patients with secondary oligomenorrhea, the presence of an androgynous sex-role model, characterized as inadequate to the age period, is invert.

4. The results of the study demonstrate the presence of sex-role transformation in girls suffering from pubertal bleeding and secondary oligomenorrhea. This, in turn, suggests that these diseases can become a form of pseudo-resolution of the conflict in the semi-role sphere.

5. Control group is characterized by a greater differentiation of interlevel connections within the $\mathrm{M} / \mathrm{F}$ symptom-complex, which provides relative freedom to their behavioral repertoire, makes girls more flexible in 
mastering various gender roles. Available models of the organization of the symptom complex $\mathrm{M} / \mathrm{F}$ in healthy girls meet age norms.

The conclusions made make it possible to raise the question of the influence of gender-role personality deviations on the formation of pathologies of the gynecological sphere and, as a result, the planning of appropriate psycho-correctional work with teenage girls. The last can be implemented in individual and group forms. The choice of techniques and the final form of work should be determined by the practical psychologist of the medical institution. But in constructing the psycho-correlation block, in our opinion, one should adhere to the general principles of correction adopted in modern medical psychology: system, differentiation, consistency, staging. It is also necessary to take into account the pathogenic factors considered in this research work, which play a predisposing role in the formation of menstrual dysfunction and contribute to their development, namely: the presence of genderrole conflict within the personality, the development of transformations of sex-role behavior and, as a result, "departure" from femininity or her assimilation through "conscription".

Thus, the tasks of psycho-correctional work can become:

1.Clarification and development of an adequate self-image of teenage girls.

2. The formation of skills of self-observation, introspection in order to level the imbalance of the sex-role sphere.

3. The formation of adaptive models of sex-role behavior.

4. The formation of adequate self-esteem as the basis of effective interpersonal relationships, including inter-gender.

5. The formation of meaning-life orientations and goal-setting.

As psycho-correctional "targets" it is possible to distinguish:

- Self-concept of personality and its gender role component.

- Sexual behavior.

- Features of interaction with the opposite sex.

- Role-based family dispositions.

- Interpersonal communications.

Psycho-correctional material can be based on client-centered, cognitive psychotherapy, it can also include elements of psychoanalysis, gestalt therapy, art therapy and the symbol of the drama. 


\section{References:}

1. Aslanyan I.E. (2016). Gipomenstrual'nyy sindrom v praktike ginekologa detskogo i podrostkovogo vozrasta [Hypomenstrual syndrome in the practice of a gynecologist in childhood and adolescence]. Reproduktivnoe zdorov'e detey i podrostkov [Reproductive health of children and adolescents]. Scientific and practical journal. Moscow: "GEOTAR-Media", no. 2, pp. 33-34.(in Russian)

2. Borisenko M.Yu., Uvarova E.V. (2015). Kliniko-laboratornye i psikhologicheskie osobennosti devochek-podrostkov s razlichnymi formami gipomenstrual'nogo sindroma [Clinical, laboratory and psychological characteristics of adolescent girls with various forms of hypomenstrual syndrome]. Reproduktivnoe zdorov'e detey i podrostkov [Reproductive health of children and adolescents]. Scientific and practical journal. Moscow: "GEOTAR-Media", no. 6, pp. 14-24. (in Russian)

3. Akgül S., Kanbur N. (2015). Premenstrual disorder and the adolescent: clinical case report, literature review, and diagnostic and therapeutic challenges. Int. J. Adolesc Med Health, V. 27(4). P. 363-8.

4. Levenets S.A., Dynnik V.A., Nachetova T.A. (2014). Narusheniya menstrual'noy funktsii u devochek-podrostkov [Menstrual dysfunction in adolescent girls]. Kharkov: Point, 196 p. (in Russian)

5. Grishko A.A., Levenets S.A., Belyaeva E.E. (2018). Polorolevye aspekty narusheniy menstrual'noy funktsii v podrostkovom vozraste [Sex-role aspects of menstrual dysfunction in adolescence]. The science newsletter of the Kherson Sovereign University. Seriya: "Psychological sciences". Vyp. 1, T. 2, pp. 178-183. (in Russian)

6. Levenets S.A., Udovikova N.A., Novokhatskaya S.V. (2016). Kharakter menstrual'noy i reproduktivnoy funktsii $\mathrm{u}$ zhenshchin s oligomenoreey $\mathrm{v}$ periode pubertata [The nature of menstrual and reproductive function in women with oligomenorrhea in the period of puberty]. Reproduktivnoe zdorov'e detey i podrostkov [Reproductive health of children and adolescents]. Scientific and practical journal. Moscow: "GEOTAR-Media”, no. 3, pp. 38-39. (in Russian)

7. Isaev D.N. (2000). Psikhosomaticheskie rasstroystva u detey: rukovodstvo dlya vrachey [Psychosomatic disorders in children: a guide for doctors]. St. Petersburg: Peter, 512 p. (in Russian)

8. A.S. Kocharyan, M.E. Zhidko, N.N. Tereshchenko, E.V. Frolova (2015). Polorolevaya psikhologiya [Sex role psychology]. Kharkov: Kharkiv National University named after V.N. Karazin, 236 p. (in Russian)

9. Kocharyan A.S. (1996). Lichnost' i polovaya rol' [Personality and Sexual Role]. Kharkov: The Basis, 127 p. (in Russian)

10. Gryshko A.A. (2018). Osoblyvosti psykhoseksualnoho rozvytku divchatpidlitkiv $\mathrm{z}$ porushenniamy menstrualnoho rozvytku [Features of psychosexual development of teenage girls with menstrual disorders]: dissertation for the degree of candidate of psychological sciences: 19.00.04. Kharkiv, 307 p. (in Ukrainian) 